\title{
Identification of subclinical cognitive impairment in chronic obstructive pulmonary disease using auditory P300 event related potential
}

\author{
Soundariya Krishnamurthy1, Yuvarajan Sivagnaname², Gokul Chandu Gumallapu ${ }^{3}$ \\ ${ }^{1}$ Department of Physiology, Sri Manakula Vinayagar Medical College and Hospital, Puducherry; ${ }^{2}$ Department of \\ Respiratory Medicine, Sri Manakula Vinayagar Medical College and Hospital, Puducherry; ${ }^{3}$ Sri Manakula Vinayagar \\ Medical College and Hospital, Puducherry, India
}

\begin{abstract}
Adequate cognitive functioning in chronic obstructive pulmonary disease (COPD) patients is essential to understand the nature of the disease, adherence to treatment, and for leading a better quality of life. While cognitive impairment in severe forms of COPD have been well documented, identification of subclinical cognitive impairment in stable COPD patients remains crucial for planning prevention strategies. Hence the present study aimed to study and compare the cognitive function between the COPD patients, and normal individuals. The cognitive function was assessed in 42 stable COPD patients and 42 normal individuals with Mini Mental State Examination (MMSE), and auditory P300 event related potentials. Baseline characteristics and the cognitive parameters were compared between the COPD patients and the normal individuals; a $\mathrm{p}<0.05$ was considered statistically significant. The latency of the P300 waves was significantly $(p<0.05)$ prolonged $(304.27 \pm 20.73$ in COPD, $291.11 \pm 24.53$ in normal individuals), and the amplitude $(4.36 \pm 1.56$ in COPD, $5.46 \pm 3.12$ in normal individuals) was significantly reduced in the COPD patients compared to the normal individuals. MMSE scores were also significantly $(p<0.001)$ different between the
\end{abstract}

\footnotetext{
Correspondence: Yuvarajan Sivagnaname, Department of Respiratory Medicine, Sri Manakula Vinayagar Medical College and Hospital, Madagadipet Puducherry 605107, India.

Mobile: +91.9789156785.

E-mail: nsivagnaname@yahoo.com

Contributions: All authors contributed equally.
}

Conflict of interest: The authors declare no potential conflict of interest.

Key words: Cognition; COPD; MMSE; P300.

Received for publication: 23 Janaury 2019

Accepted for publication: 10 May 2019.

CCopyright S. Krishnamurthy et al., 2019

Licensee PAGEPress, Italy

Monaldi Archives for Chest Disease 2019; 89:1039

doi: 10.4081/monaldi.2019.1039

This article is distributed under the terms of the Creative Commons Attribution Noncommercial License (by-nc 4.0) which permits any noncommercial use, distribution, and reproduction in any medium, provided the original author(s) and source are credited.
COPD patients $(26.97 \pm 0.89)$, and the normal individuals (27.80 \pm 0.83$)$. Cognition may be affected even at the earlier stages of the disease among the COPD patients, as evident by changes in the P300 values. Auditory P300 event related potential may be used as an adjunct to the routine MMSE examination, as it serves as an effective tool in identifying the cognitive impairment in different stages of COPD. This may help the patients to adopt prevention strategies that help to avoid adverse effects on cognition in future.

\section{Introduction}

Chronic obstructive pulmonary disease (COPD) may be considered as a complex disorder associated with several systemic consequences, and comorbidities [1]. Understanding and identification of the comorbidities in COPD may help to recognize the pattern of the disease, and in planning interventional strategies. Adequate cognitive functioning in patients is essential to understand the nature of the disease, adherence to treatment, and for leading a better quality of life. Cognitive dysfunction may also be associated with increased morbidity and mortality. There has been increased recognition of cognitive impairment in patients with severe COPD in the past few years [2,3]. Hypoxemia, systemic inflammation, associated comorbidities like smoking, and several other factors have been linked with cognitive dysfunction in COPD [4].

Literature search on cognitive functioning in COPD patients revealed conflicting results. While some studies identified cognitive impairment in end stages of COPD [5], and during acute exacerbations [6], few studies identified mild cognitive impairment even in non-hypoxemic stable COPD patients [7]. Hence degree of cognitive dysfunction in different stages of COPD need to be explored. Prior studies that studied cognitive function in COPD patients relied on MMSE mini-mental state examination (MMSE), and other battery of tests, which are well known to be influenced by several confounding factors $[8,9]$.

Event related potentials are the voltage changes induced within the brain in response to a variety of sensory, motor and cognitive processes. P300 is a long latency endogenous cortically generated positive wave form of auditory event related potential, with maximum peak around 300 milliseconds, post stimulus [10,11]. It is widely recognized as a valid tool in assessing the cognitive function. The changes in P300 amplitude reflect the nature of information processing and P300 latency is related with cognition ability, and attention. Unlike other psychometric tests, event related potentials are not influenced by personality traits, or education- 
al status [12]. P300 has a wide clinical utility as evidenced by its usage in assessment of cognitive impairment in conditions like cirrhosis [13], thyroid dysfunction [14], dementia [15], and alcoholism [16]. P300 may provide a sensitive measure of subclinical cognitive dysfunction, unidentified by other psychometric tests, at earlier stages of the disease.

Hence the present study aimed to assess the cognitive dysfunction in patients with COPD using the electrophysiological auditory P300 event related potentials.

\section{Patients and Methods}

The present cross section study was conducted at the research laboratory, Department of Physiology of our Institution, after obtaining permission from the Institutional Ethics Committee (Ref No. 19/2017).

\section{Study participants and sample size}

The sample size was estimated to be 84 , using "openEpi" software ver. 3.03 taking into consideration mean (SD) P300 values of COPD, and normal study participants from a previous study [7]. Among the 84 subjects, 42 subjects were COPD patients, recruited from the patients attending the Pulmonology outpatient department (OPD) of our institution, and 42 subjects were normal subjects, selected from the attenders accompanying the patients. The participants were divided in stable COPD patients (Group 1) and normal subjects (Group 2). The study duration was April to September 2017. Inclusion criterion was a diagnosed stable COPD based on GOLD criteria in the age group

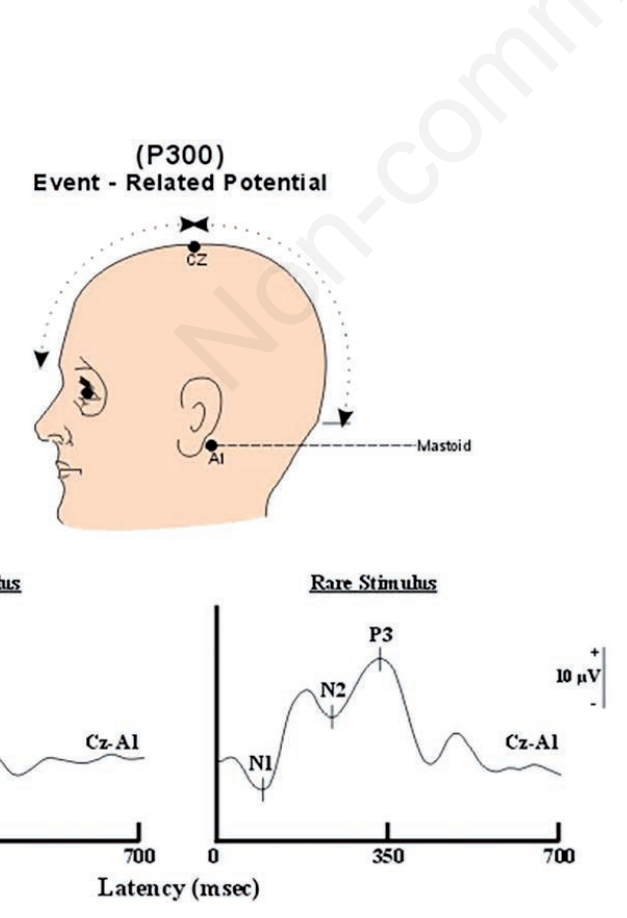

Figure 1. Electrode placement for P300. Reproduced from the manual of RMS EMG EP MK II equipment (Electromyography, Evoked potential machine, MK II model, Recorders and Medicare System Private Ltd., Chandigarh, India), with permission. of 40-60 years and exclusion criteria were: age $>60$ years, acute exacerbation of COPD or any other respiratory illness, any other systemic illness (diabetes, hypertension), individuals on drugs, individuals with hearing loss, clinically evident cognitive dysfunction, cardiac illness.

\section{Methodology}

Informed consent was obtained from all the study participants. After obtaining medical history, a thorough physical examination was performed on all the study participants. All demographic details were recorded through a structured questionnaire. Then the anthropometric measurements like height, weight were recorded in all the study participants.

Stable COPD patients (based on GOLD criteria), as diagnosed by the pulmonologist satisfying the inclusion and exclusion criteria, were recruited from the outpatients attending the pulmonology outpatient department.

Two tools were used to assess the cognitive functioning of the COPD patients. The MMSE, a questionnaire comprising of 11 questions, was used, making to a total score of 30. Auditory P300 test was the other tool used to assess the cognitive functioning. Pulse oximetry was used to assess the oxygen saturation.

\section{Recording of P300}

Subjects were informed about the nature of procedure. P300 was recorded by an auditory oddball paradigm, in which two types of tones were presented to the participants through a headphone, rare tone $(2 \mathrm{KHz})$, and frequent tone $(1 \mathrm{KHz})$ of $85 \mathrm{~dB}$ were applied on both ears together in $20 \%$ and $80 \%$ in frequency in random through headphones. Participants were instructed to recognize the rarer type of the tone and count aloud each time they heard the rare tone. Total 300 stimuli were applied at rate of $1 \mathrm{stimuli} / \mathrm{s}$. The bioelectrical signals were picked up from the scalp by using $\mathrm{Ag} / \mathrm{AgCl}$ electrodes placed as per 10-20 international system of placement. The recording sites on scalp were cleaned with spirit. After applying electrolyte paste on recording surface, one active electrode was attached on vertex $\left(C_{z}\right)$, one as ground electrode to forehead $\left(F_{z}\right)$ and two reference electrodes to right and left mastoid designated as $\mathrm{A} 1$, and A2, respectively (Figure 1). The skin to electrode impedance was kept below $5 \mathrm{~K}$ ohms. Subjects were asked not to sleep and identify the rare stimulus, counting in loud voice. The signals were recorded on the screen of EMG EP MK II equipment (Electromyography, Evoked potential machine, MK II model, Recorders and Medicare System Private Ltd., Chandigarh, India). Two reproducible recordings were taken for a subject, and averaged together to obtain the final measurement. As the attention to the rare tone is a sign of cognition, the latency and amplitude of P300 wave for rare stimuli were considered for the analysis. P300 amplitude was measured as the peak amplitude between 250-500 ms, post-stimulus. The P300 latency was measured as the timeperiod between stimulus onset and peak amplitude (Figure 2).

The baseline characteristics and the cognitive parameters were compared between the normal, and COPD patients using unpaired $t$-test. The correlation between oxygen saturation, and the cognitive parameters were assessed by Pearson's correlation test; a pvalue $<0.05$ was considered statistically significant. SPSS version 20 was used for statistical analysis. 


\section{Results}

Of the total 84 study participants, 42 were stable COPD patients, 42 were normal subjects. The mean age of the study participants were $51.52 \pm 6.17$ years. 64 of the study participants were males, and 20 were females. Among the COPD patients, 17 were non- smokers, 18 were smokers, and 7 were ex-smokers. The mean duration of illness among the COPD patients were around $6.33 \pm 3.59$ years, and the mean pack years among the smokers were around 26.16 \pm 21.42 .

Table 1 shows the comparison of the baseline characteristics between the COPD group, and normal subjects. FEV $\mathrm{FVVC}_{1}$, $\mathrm{FEV} 1 / \mathrm{FVC}, \mathrm{PEF}, \mathrm{FEV}_{1} \%$ predicted values and $\mathrm{sPo}_{2}$ were significantly lower among COPD patients compared to the normal individuals $(\mathrm{p}<0.001)$.

Table 2 shows the comparison of the cognition parameters between the COPD patients, and the normal individuals. The latency of the P300 wave for the rare tone stimuli was significantly prolonged, and the amplitude was significantly lower in the COPD patients compared to the normal subjects $(p<0.05)$. However there was very significant difference in the MMSE scores between the COPD patients, and the normal individuals $(p<0.001)$. Around 7 COPD patients had MMSE scores $<24$, the recommended cut-off to identify low MMSE scores.

Table 3 shows the comparison of the cognitive parameters between the different stages of COPD, based on GOLD criteria. There was a significant difference in the latency of P300 between stage 1 COPD and stage 2 COPD and also between stage 2 COPD and stage 3 COPD. MMSE scores were significantly lower in stage 2 and stage 3 COPD compared to the stage 1 COPD patients. None of our study subjects were in stage 4 COPD based on GOLD criteria.

Table 4 shows the correlation assessed between the oxygen sat-

Table 1. Comparison of baseline characteristics between COPD patients and normal individuals.

\begin{tabular}{|c|c|c|}
\hline Parameters & Group 1 (COPD)n=42 & Group 2 (normal)n=42 \\
\hline Age & $52.21 \pm 6.45$ & $50.83 \pm 5.88$ \\
\hline $\mathrm{FEV}_{1}$ & $1.21 \pm 0.47$ & $2.64 \pm .30^{*}$ \\
\hline FVC & $1.92 \pm 0.58$ & $3.12 \pm 0.30^{*}$ \\
\hline $\mathrm{FEV}_{1} / \mathrm{FVC}$ & $57.65 \pm 7.91$ & $84.68 \pm 5.27 *$ \\
\hline PEF & $2.12 \pm 0.87$ & $6.35 \pm 1.45^{*}$ \\
\hline $\mathrm{sPO}_{2}$ & $95.02 \pm 1.60$ & $98 \pm 0.82 *$ \\
\hline $\mathrm{FEV}_{1} \%$ PRED & $56.69 \pm 20.62$ & $84.83 \pm 18.58 *$ \\
\hline
\end{tabular}

Values expressed as mean $\pm \mathrm{SD}$; $\mathrm{FEV}_{1}$, forced expiratory volume in $1 \mathrm{~s} ; \mathrm{FVC}$, forced vital capacity; PEF, peak expiratory flow; $\mathrm{SPO}_{2}$, oxygen saturation; $\mathrm{FEV}_{1} \% \mathrm{PRED}$, FEV $\%$ of predicted value; ${ }^{*} \mathrm{p}<0.001$.

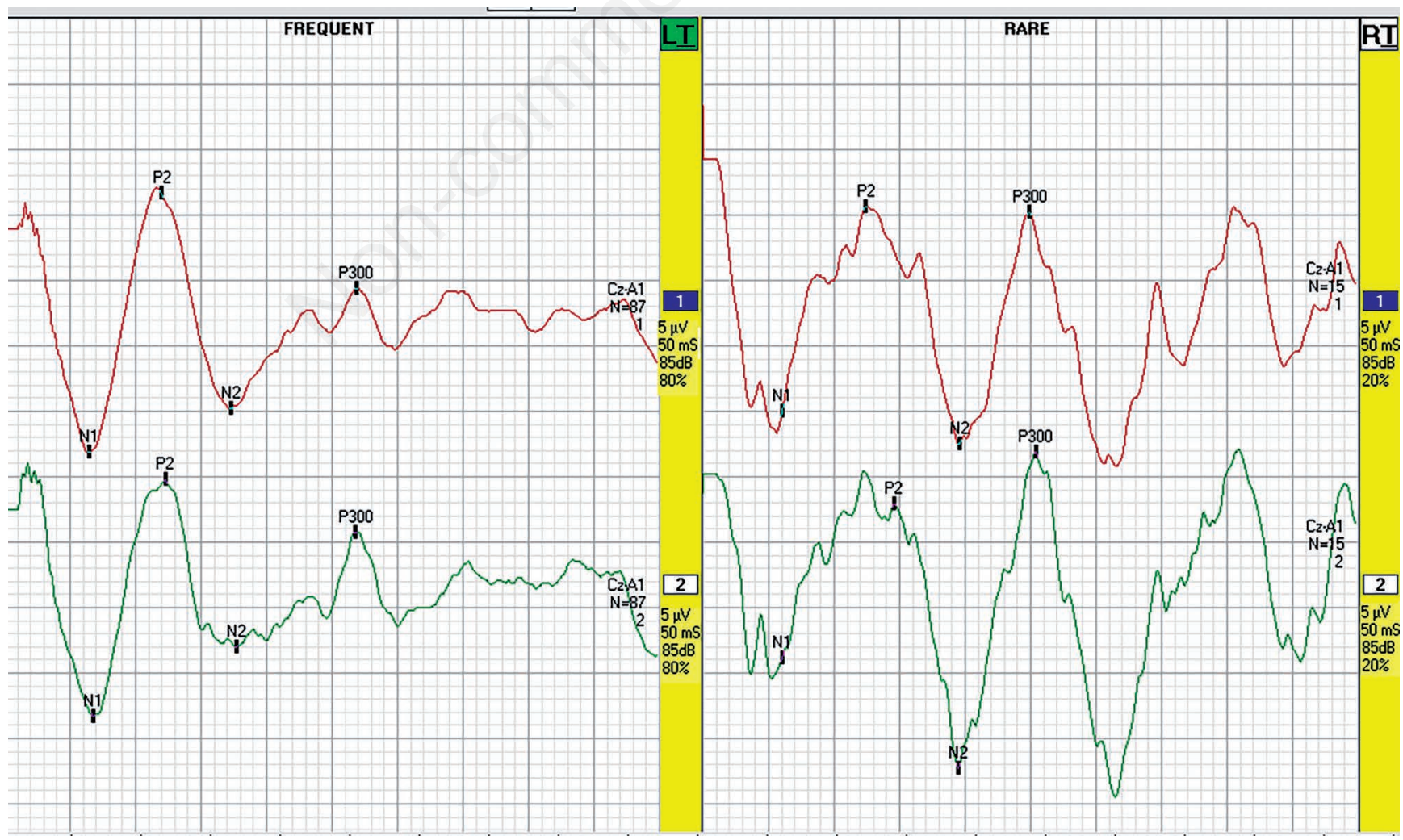

Figure 2. P300 Wave form for frequent and rare stimuli of one of our COPD patients. 
uration levels, $\mathrm{FEV}_{1}$ percentage predicted values, MMSE and the P300 event related potentials. Though a negative correlation was identified between the latency of P300, and the oxygen saturation levels, MMSE scores it was not statistically significant. However a significant negative correlation $(\mathrm{p}<0.05)$ was observed between the latency of $\mathrm{P} 300$ and $\mathrm{FEV}_{1}$ percentage predicted values and a significant positive correlation $(p<0.001)$ was observed between amplitude of $\mathrm{P} 300$ and $\mathrm{FEV}_{1}$ Percentage predicted values.

\section{Discussion}

Auditory P300 event related potential is an electrophysiological test, widely recognized as a valid tool in assessing the cognitive function. Literature search reveals that even mild cognitive impairment induces changes in the latency, and the amplitude of the P300 wave [17].

Chronic obstructive pulmonary disease is well known to be associated with irreversible loss of lung function, also produces deleterious extra pulmonary systemic effects [18]. Cognitive impairment is one such extra pulmonary manifestation [19]. The results of the present study suggest a strong association between cognitive dysfunction and COPD.

In our study, the latency of the auditory P300 potential is prolonged in COPD patients compared to the normal individuals. The amplitude of the P300 wave obtained for the rare tone stimuli was also significantly reduced compared to the normal individuals. These results suggest that cognitive dysfunction may start sub clinically even in earlier stages of the COPD.
Similar results were reported by other studies [7,20] Gupta et al. observed significant cognitive dysfunction in stable COPD patients with no hypoxemia [7]. Liesker et al. also observed significant cognitive impairment in stable COPD patients without hypoxemia [20]. However, Incalzil and colleagues reported that nonhypoxemic COPD patients do not suffer from cognitive dysfunction [21]. In our study, it is clearly evident that MMSE scores and P300 parameters are significantly lower in the stage 2 and stage 3 COPD patients, compared to the stage 1 COPD patient. While cognitive impairment in moderate and severe forms of COPD are well addressed, and found to be related to the severity and duration of the disease [22,23], disparities do exist in the prevalence of cognitive impairment in non- hypoxemic patients. These disparities could be attributed to the difference in sample size and psychometric tests used to assess the cognitive dysfunction. Our study stands different in a way that it has used two tools to assess the cognitive dysfunction. Both the tests in our study reveal a significant difference between COPD, and normal patients. MMSE is well known to be influenced by several confounding factors. Hence auditory P300 may be used as an adjunct to the routine MMSE in identifying subclinical cognitive impairment.

In our study there was no statistically significant correlation between the oxygen saturation levels, and the P300 values. These could be attributed to the fact that most of the patients had saturation levels higher than $92 \%$. Though hypoxemia is suggested to be the predominant factor causing cognitive dysfunction in COPD patients [19], influence of other factors like systemic inflammation, and ill effects of smoking cannot be excluded [24] A significant correlation has been observed between $\mathrm{FEV}_{1}$ percentage predicted values and the latency, amplitude of P300 waveforms,

Table 2. Comparison of cognition parameters between COPD patients and normal individuals.

\begin{tabular}{lccc} 
Parameters & \multicolumn{2}{c}{ P300 values of rare stimuli at $\mathrm{C}_{\mathrm{z}}$} & MIVSE Score \\
Latency & Amplitude & $26.97 \pm 0.89 * *$ \\
Group 1 (COPD) & $304.27 \pm 20.73^{*}$ & $4.36 \pm 1.56^{*}$ & $27.80 \pm 0.83$ \\
Group 2 (Normal) & $291.11 \pm 24.53$ & $5.46 \pm 3.12$ & \\
\hline
\end{tabular}

Values expressed as mean $\pm \mathrm{SD}$; MMSE, mini mental state examination; ${ }^{*} \mathrm{p}<0.05 ;{ }^{* *} \mathrm{p}<0.001$.

Table 3. Comparison of the cognition parameters between the different stages of COPD based on GOLD criteria.

\begin{tabular}{lccc} 
Parameters & \multicolumn{2}{c}{$\begin{array}{c}\text { P300 values of rare stimuli at } \mathrm{C}_{z} \\
\text { Latency }\end{array}$} & $\begin{array}{c}\text { MIMSE Score } \\
\text { Stage 1 COPD }\end{array}$ \\
Stage 2 COPD & $292.44 \pm 14.8$ & $4.79 \pm 2.08$ & $27.85 \pm 0.37$ \\
\hline Stage 3 COPD & $298.95 \pm 19.9^{*}$ & $4.79 \pm 1.44$ & $26.94 \pm 0.80^{*}$ \\
\hline
\end{tabular}

Values expressed as mean $\pm \mathrm{SD} ;{ }^{*} \mathrm{p}<0.05$ between stage 1 and $2 \mathrm{COPD} ;{ }^{*} \mathrm{p}<0.05$ between stage 1 and $3 \mathrm{COPD} ;{ }^{\circledR} \mathrm{p}<0.05$ between stage 2 and 3 COPD; MMSE, mini mental state examination; GOLD, global initiative for chronic obstructive lung disease.

Table 4. Correlation of P300 and oxygen saturation levels.

\begin{tabular}{|c|c|c|c|c|}
\hline Parameters & \multicolumn{2}{|c|}{$\begin{array}{l}\text { Latency } \\
\text { P300 Latency for rare stimuli at } C_{z}\end{array}$} & \multicolumn{2}{|c|}{$\begin{array}{l}\text { Amplitude } \\
\text { P300 amplitude for rare stimuli at } C_{2}\end{array}$} \\
\hline Oxygen saturation & 0.059 & 0.592 & 0.159 & 0.148 \\
\hline $\mathrm{FEV}_{1} \%$ PRED & 0.281 & $0.010^{*}$ & 0.350 & $0.001^{* *}$ \\
\hline MMSE & 0.190 & 0.083 & 0.137 & 0.213 \\
\hline
\end{tabular}

MMSE, mini mental state examination; $\mathrm{FEV}_{1} \%$ PRED, $\mathrm{FEV}_{1} \%$ of predicted value; ${ }^{*} \mathrm{p}<0.05,{ }^{* *} \mathrm{p}<0.001$. 
which signifies the increased risk of cognitive impairment with the severity of the disease [22,23]. In our study, oxygen saturation was assessed using pulse oximeter and arterial blood gas analysis was not performed as most of our patients are clinically stable.

\section{Conclusions}

Adequate cognitive functioning in patients is essential to understand the nature of the disease, adherence to treatment, and for leading a better quality of life. COPD patients are prone for subtle changes in their cognitive function even in the earlier stages of the disease, without hypoxia. Hence assessment of cognitive functions should be considered in the management of COPD. Auditory P300 event related potential may be used as an adjunct to the routine MMSE examination, as it serves as an effective tool in identifying the cognitive impairment at different stages of COPD.

\section{References}

1. Agusti A, Soriano JB. COPD as a systemic disease. COPD 2008;5:133-8.

2. Dodd JW, Getov SV, Jones PW. Cognitive function in COPD. EurRespir J 2010;35:913-22.

3. Hung WW, Wisnivesky JP, Siu AL, Ross JS. Cognitive decline among patients with chronic obstructive pulmonary disease. Am J Respir Crit Care Med 2009;180:134-7.

4. Torres-Sánchez I, Rodríguez-Alzueta E, Cabrera-Martos I, et al. Cognitive impairment in COPD: a systematic review. J Bras Pneumol 2015;41:182-90.

5. Salik Y, Ozalevli S, Cimrin AH. Cognitive function and its effects on the quality of life status in the patients with chronic obstructive pulmonary disease (COPD). Arch Gerontol Geriatr 2007;45:273-80.

6. Kirkil G, Tug T, Ozel E, et al. The evaluation of cognitive functions with P300 test for chronic obstructive pulmonary disease patients in attack and stable period. Clin Neurol Neurosurg 2007;109:553-60.

7. Gupta PP, Sood S, Atreja A, Agarwal D. A comparison of cognitive functions in non-hypoxemic chronic obstructive pulmonary disease (COPD) patients and age-matched healthy volunteers using mini-mental state examination questionnaire and eventrelated potential, P300 analysis. Lung India 2013;30:5-11.

8. Özge C, Özge A, Ünal Ö. Cognitive and functional deterioration in patients with severe COPD. Behav Neurol 2006;17:121-30.

9. Isoaho R, Puolijoki H, Huhti E, et al. Chronic obstructive pul- monary disease and cognitive impairment in the elderly. Int Psychogeriatr 1996;8:113-25.

10. Katada E, Sato K, Ojika K, Ueda R. Cognitive event-related potentials: useful clinical information in Alzheimer's disease. Curr Alzheimer Res 2004;1:63-9.

11. Frodl T, Hampel H, Juckel G, et al. Value of event-related P300 subcomponents in the clinical diagnosis of mild cognitive impairment and Alzheimer's Disease. Psychophysiolog 2002;39:175-181.

12. Bennys K, Portet F, Touchon J, Rondouin G. Diagnostic value of event-related evoked potentials N200 and P300 subcomponents in early diagnosis of Alzheimer's disease and mild cognitive impairment. J Clin Neurophysiol 2007;24:405-12.

13. Sexena N, Bhatia M, Yoshi YK, et al. Utility of P300 auditory event related potential in detecting cognitive dysfunction in patients with cirrhosis of the liver. Neurol India 2001;49:350.

14. Dejanović M, Ivetić V, Nestorović V, et al. The value of P300 event related potentials in the assessment of cognitive function in subclinical hypothyroidism. Minerva Endocrinol 2017;42:15-23.

15. Egerházi A, Glaub T, Balla P, et al. P300 in mild cognitive impairment and in dementia]. Psychiatr Hung 2008; 23:34957.

16. Maurage $P$, Philippot $P$, Verbanck $P$, et al. Is the $P 300$ deficit in alcoholism associated with early visual impairments (P100, N170)? An oddball paradigm. Clin Neurophysiol 2007;118: 633-44.

17. Medvidovic S, Titlic M, Maras-Simunic M. P300 evoked potential in patients with mild cognitive impairment. Acta Informatica Medica 2013;21:89-92.

18. Huertas A, Palange P. COPD: a multifactorial systemic disease. Ther Adv Respir Dis 2011;5:217-24.

19. Thakur N, Blanc PD, Julian LJ, et al. COPD and cognitive impairment: the role of hypoxemia and oxygen therapy. Int J Chron Obstruct Pulmon Dis 2010;5:263-9.

20. Liesker JJ, Postma DS, Beukema RJ, et al. Cognitive performance in patients with COPD. Respir Med 2004;98:3516.

21. Incalzil RA, Bellia V, Maggi S, et al. Mild to moderate chronic airways disease does not carry an excess risk of cognitive dysfunction. Aging Clin Exp Res 2002;14:395-401.

22. Reeves RR, Struve FA, Patrick G, Payne DK, Thirstrup LL. Auditory and visual P300 cognitive evoked responses in patients with COPD: relationship to degree of pulmonary impairment. Clin Electroencephalogr 1999;30:122-5.

23. Villeneuve S, Pepin V, Rahayel S, et al. Mild cognitive impairment in moderate to severe COPD: a preliminary study. Chest 2012;142:1516-23.

24. Andrianopoulos V, Gloeckl R, Vogiatzis I, Kenn K. Cognitive impairment in COPD: should cognitive evaluation be part of respiratory assessment? Breathe 2017;13:e1-e9. 
